\title{
Divergences in American and Chinese Scholars' Researches on Yang Xiong's Fu
}

\author{
Lu Jie ${ }^{1,2}$ \\ ${ }^{1}$ Foreign Language College, Chengdu University of Information Technology, China \\ ${ }^{2}$ College of Literature and Journalism, Sichuan University, China
}

Copyright $\bigcirc 2017$ by authors, all rights reserved. Authors agree that this article remains permanently open access under the terms of the Creative Commons Attribution License 4.0 International License

\begin{abstract}
American sinologists and Chinese scholars' researches on Yang Xiong's Fu show heterogeneity and variation in their perspectives, paradigms and views due to the differences in cultural moulds and poetic traditions. The primary divergences lie in their researching backgrounds and purposes, perceptions of the literary and ideological value of Yang Xiong's Fu, and their comments on Yang's imitation of his predecessors in his $\mathrm{Fu}$ writing. American sinologists develop fresh insights in this research and their erudition and precision cast new light on their Chinese peers. A mutual interpretation, testimony, complementation and communication between Chinese and American cultures can be gained through the study on divergences in researches on Yang Xiong's Fu carried out by Chinese and American scholars.
\end{abstract}

Keywords Yang Xiong, Han Fu, Fan Li Sao, David R. Knechtges, Variation Study

\section{Introduction}

$\mathrm{Han} \mathrm{Fu}$, as a highly ornamental and much-touted official literary form, was once very prevalent especially in the Han Dynasty of China. However it later became heavily criticized, even from its own practitioners, such as Mei Gao (枚鼻), Yang Xiong (扬雄) and Cai Yong (蔡邑). For a very long period of time, it has been mistaken as the synonym of "formalism" which carries a derogatory meaning in Chinese literary arena due to its special historical and political background. A typical example to show its miserable position is that it was denounced by Zheng Zhenduo（郑振 铎）as an “anti-realist representative". Therefore, Fu didn't gain its due honor from Chinese literati until the Third Plenary Session of the 11th Central Committee of the Chinese Communist Party. After the "Double Hundred" Policy proposed in this great session, Chinese scholars' comments on $\mathrm{Fu}$ gradually became objective, sensible and rational. They reassessed Fu's value from a new historicist perspective and relocated Fu's literary status in China's history. Gong Kechang (龚克昌), a contemporary expert in Fu study put forward: "Han Fu maybe is not as splendid as Tang poetry, Song Ci, Yuan Qu and Ming and Qing's Novels...... but it demonstrates the reality of great Han dynasty's prosperity and depicts Han's spirit and atmosphere. It is the starting point of ancient Chinese literary self-consciousness; it accumulates precious experiences for the development of China's ancient literature; it creates various colorful artistic techniques of expression. "[1]Along with the reassessment of $\mathrm{Fu}$, some masters in this literary form begin to draw more academic attention. Study of some $\mathrm{Fu}$ writers, such as Sima Xiangru (司马相如), Ban Gu (班 固) and Zhang Heng (张衡) are excessively fruitful, no matter whether in terms of quality or quantity. But Yang Xiong's $\mathrm{Fu}$ is quite rarely explored, which remains a mystery for many oversea sinologists. Actually, Chinese scholars' interest in Yang Xiong mainly lies in his works like " $\mathrm{Fa}$ Yan"(《法言》), “Tai Xuan" ( 《太玄》) and "Fang Yan" (《方言》), not his Fu writings. In their points of view, Yang Xiong's systematic philosophical and linguistic thoughts outweigh his accomplishment in $\mathrm{Fu}$ writings. However, Western scholars' enthusiasm in Yang Xiong study is just contrary to that of their Chinese counterparts. They speak highly of Yang Xiong's Fu and many of them regard him as a talented $\mathrm{Fu}$ writer who is even more successful than his predecessor Sima Xiangru. The study of Yang Xiong's Fu presents apparent divergences and variations between Chinese and American scholars, which is like a description make by Liu Hsieh（刘䞏） in his “The Literary Mind and the Carving of Dragons" ( 《文心雕龙》) that literature is like plants of the same species but variation and mutation happen if being planted in different soil and solar environment. This essay explores the divergences and variations between Chinese and American scholars on this issue from their different research perspectives, paradigms and conclusions in the hope that Western and Eastern civilizations can reach mutual interpretation, testimony, complementation and communication. 


\section{American Scholars' Different Background for Researches of Yang Xiong's Fu}

Due to China's promotion of realist literature and suppression of formalist literature since the establishment of the Republic of China, and the subsequent movement of "elimination of the four stereotypes" in "the Great Cultural Revolution", Fu's status plummeted and lingered in the bottom of literary pyramid. From the 1950 s to 1980 s, nobody had overtly carried academic researches on Fu. But ironically, it was just in this period that Yang Xiong's Fu caught the eye of American sinologists with its unique themes and outstanding rhetorical techniques. Consequently American sinologists' study in this field began to boom.

\subsection{The Commencement of American Sinologists' Study on Yang Xiong}

David R. Knechtges finished his doctoral dissertation "Yang Shyong, the Fuh, and Hann Rhetoric" in University of Washington in 1968, which is a big event in respect of Yang Xiong's study in America. Later he published "Two Studies on the Han Fu" and "The Han rhapsody: a study of the fu of Yang Hsiung" respectively in 1968 and 1976. His sustained interest in Yang Xiong's $\mathrm{Fu}$ was like a catalyst which accelerated many of his American peers to study Yang Xiong — a seriously underestimated Chinese literary master. In 2015, "International sinology" published the Chinese version of the preamble of Knechtges' "The Han Rhapsody: A Study of the $\mathrm{Fu}$ of Yang Hsiung[52B.C-A.D.18]" (Cambridge: Cambridge University Press, 1976). The translator Jiang Wenyan（蒋 文燕) confidently announced that although the book was published more than four decades ago, it is now still thought-provoking because of its research paradigms and conclusions on Yang Xiong's Fu obviously opposite to those of scholars in Mainland China. In addition, it is still rather inspiring for the present domestic study on $\mathrm{Fu}$ since it provides abundance of detailed and accurate information and material, together with tight arguments and objective attitudes. [2]

Besides, many other famous international sinologists added matches in the conflagration of study of Yang Xiong's Fu. Burton Watson's "Chinese Rhymed Prose: Poems in the Fu Form from the Han and Six Dynasty Periods", James Robert Hightower's "Topic in Chinese Literature", Timoteus Pokora's "Huan T'an and Yang Hsiung on Ssu-ma Hsiang-ju: Some Desultory Remarks on History and Tradition" all spontaneously focused on the literary value, artistic aestheticism, and the literary status of Yang Xiong's Fu.

\subsection{The Development of American Sinologists' Study on Yang Xiong}

Since the opening-up policy at the end of the 1970's, literary status of $\mathrm{Fu}$ has been restored to some extent, and the study on Yang Xiong's Fu has consequently get warm again after a cold spell. But influenced by some negative remarks on Fu from Yang's own book "Fa Yan", Chinese scholars are fonder of examination and annotation, philosophical interpretation, biographical introduction, and even calligraphy study than Yang's Fu. Fu writing has been a taboo in Yang Xiong's study in mainland China for a long time. Whereas American scholars' study on Yang Xiong achieved an all-round development and a sustainable benign growth: Knechtges' "The Han shu Biography of Yang Xiong" in 1982 deepened and expanded Western scholars' understanding about Yang Xiong and his $\mathrm{Fu}$, which stimulated many scholars to write essays on this issue. In 1997, Knechtges translated Gong Kechang's "Studies of the Han Fu" into English. The chapter about Yang Xiong's Fu was particularly controversial, which made Bernhard Fuehrer from the University of London School of Oriental and Africa Study (SOAS) write essays to respond. The translation of Gong's work should undoubtedly be regarded as a milestone in Sino-Us cultural exchange. In 2002, "Court Culture and Literature in Early China", a book with some important essays and a chapter of exclusive introduction to Yang Xiong's Fu was published. Knechtges called Yang a "court poet in the late West Han Dynasty" and thought that Chinese didn't pay enough attention to him despite its enhanced present interest in Fu. He said: "like Sima Xiangru, Yang Xiong is equally important in the process of the formation of fu."'[3] By the way, this book was translated into Chinese by Su Longrui(苏隆瑞), one of Knechtges' students. The translated book of Knechtges' work provided a good chance for Chinese scholars to know Yang Xiong's influence in Western civilization.

Besides Knechtges' study, the most prominent, there are also some other young scholars choosing Yang Xiong as their research subject. In 1983, Michael Barnet finished his doctoral dissertation "Han Philosopher Yang Xiong: An Appeal for Unity in an Age of Discord"; in 2010, Mark Gerald Pitner finished "Embodied Geographies of Han Dynasty China: Yang Xiong and his Reception" and Nicholas Morrow Williams" The Brocade of Words: Imitation Poetry and Poetics in the Six Dynasties". Those young scholars' studies passed on Yang Xiong's thoughts from generation to generation and the study of Yang Xiong's $\mathrm{Fu}$ is like a plant transplanted from China to America and survives perfectly on this new soil.

In short, American sinologists' study is an unavoidable part in the constitution of global Yang Xiong study. Their perspectives and perceptions are necessary complements to China's relevant study. Their "otherness" is an increasingly attractive study object which fuels "the study of Yang Xiong's Fu" in China. Chinese scholars attempt to explore effective ways for the "internationalization" and "canonicalization" of Chinese classic literature via analyzing the roots in Western civilization that cause these divergences and variations in this research. 


\section{Divergences on the Literary and Ideological Value of Yang Xiong's Fu}

Due to the big cultural gap, different time and social backgrounds of research on Yang Xiong's Fu, and the dichotomy in paradigms and thinking habits between China and America, Chinese and American scholars disagree on the literary and ideological value of Yang Xiong's Fu.

There are many different opinions on the literary and ideological value of Yang Xiong's Fu between China and America, among which the comments on "Fan Li Sao" (《反 离骚》), or in Knechtges' translation “The Faan-Sau", is the most conspicuous dispute. In Chinese scholars' eyes, the most respected and admired $\mathrm{Fu}$ written by Yang Xiong should be his "four great Fu", including "Her-dong fuh" (《河东赋》), "Yue-lieh fuh" (《羽猎赋》), "Gan-chyuan fuh" (《甘泉赋》) and “Charng-yangfuh" (《长杨赋》). They are said to be the embodiments of Yang's optimism, his concern about the peasants' misery, his opposition to the emperor's extravagancy and his longing for the unity of motherland. While as for "The Faan-sau", it has been always recurring acid-tongued criticism because of its negative remarks on Chiu Yuan (屈原). Zhu Xi (朱喜), an excellent scholar in the Song dynasty said: "Yang Xiong is certainly guilty for what he said about Chiu Yuan, and this writing is actually a kind of defamation." [4]Liu XiZai (刘熙载) in the Qing dynasty said: "Ban Gu's comment that Chiu Yuan was fond of showing off derives from Yang Xiong's Fan Li Sao."[5] Gong Kechang pointed out that "The Faan-sau demonstrates Yang Xiong's weakness in personality and a latent deep-rooted bad Taoist thought of 'quietness and inaction'. His belief that 'Chiu Yuan should have acted like the dragon that hides in a deep pool waiting for a cloud to take him up instead of drowning himself in the river.' is much inferior to Chiu Yuan's ideological level and militant spirit." [6]Zhu Xi and Gong Kechang's remarks are very representative of Chinese orthodox intellectuals' thoughts about the Faan-sau. They criticized it on the basis of Yang Xiong's attitude towards Chiu Yuan's suicide instead of the writings' own literary and ideological value. Although a minority of Chinese scholars, such as Hu Yinglin (胡应麟) and Li Zhi (李贽) dared to rehabilitate its sullied reputation, they only made use of the run-around that Yang Xiong's opposition to Chiu Yuan was indeed a disguised enthusiasm to Chiu Yuan instead of a declaration of its own value. All Chinese scholars are influenced by Confucianism without exception when they access the Faan-sau. Confucius pursued his life-time doctrine to do what is impossible against all odds if only he could be useful for society. This kind of Confucius principle of "going into society" has been integrated into China's culture for thousands of years. Therefore, for Chinese traditional scholars, there is no dilemma like Hamlet's question of "to be or not to be" - in their minds, "what one should do" is certainly beyond "what one can do". Chiu Yuan's attempt to awaken his Lord with his suicide is of course what one cannot do, but it is a matter of "what one should do" out of duty and justice. This is the reason why Yang Xiong's questioning Chiu Yuan's suicide incurred so many criticisms and was regarded as a heresy.

However, this controversial writing turns out to be much-touted in American scholar Knechtges' study. In his doctoral dissertation in 1968, he made a thorough introduction and research on Yang Xiong's biography and major writings. His supervisory committee commented that his dissertation demonstrated "his intimate familiarity with the literature, his unusual, even exceptional, skill in handing the philological and literary problem of his texts, a sharp acumen when confronted with problem textual criticism, and, above all, a well-balanced reasoning capacity based on a broad knowledge of comparative phenomena, on a wide acquaintance with conceptual criteria."'[7] His exceptional skill in handing his texts is extraordinarily embodied in his analysis of the Faan-sau. First of all, he rearranged the order of introducing Yang Xiong's Fu. He broke the usual order adopted by Chinese scholars to introducing the "the four great $\mathrm{Fu}$ " prior to all the other writings. He put the Fann-sau as the leading one, and then followed by Shuu-du fuh (《蜀 都赋》) and "the four great fu". Why did he promote it to the highest position beyond the "four great fu" despite Chinese scholars' avalanche-like criticism on it? I think this is mainly due to the fact that his identity endows him an "otherness" of background and standpoint. When analyzing the Faan-sau, he pointed out that Yang Xiong's motive for writing it was different from those other distinguished scholar-poets of the age at one time or another trying their hand at writing an imitation of Chiu Yuan Fu. Yang Xiong was not so much to imitate the Li Sao (《离骚》), actually, "he was the first to write a poem overtly condemning Chiu Yuan's (屈原) suicide. Jea Yih (贾谊) had expressed mild disapproval of Chiu Yuan's behavior, but did not develop his criticism to any extensive degree. Essentially Yang has written a fuh in sau meter and sau language that amounts to a desultory commentary on Chiu Yuan's poem." [8]Many people will deduce that Knechtges' praise of the Faan-sau possibly comes from his ignorance of Chinese traditional criticisms on it. But if they really think so, they are woefully wrong. In the fourth chapter of his dissertation, he mentioned that the Faan-sau had never been considered a distinguished piece of writing. To prove this, he quoted Liou Shye's (刘妿思) comments and said "Liou Shye is generally complimentary to Yang Shyong, describes its failings in extremely apt terms: 'As to the condolence offered by Yang Shyong to Chiu Yuan, it was a work of great labor but little merit. Yang was deeply intent on reversing the point of view found in the Li sau; and for this reason, his work is characterized by clumsy expressions and uncouth rhyme." He then drew the conclusion that "the main importance of Yang Shyong's poem is its articulation of a 'Confucian' opposition to Chiu Yuan's suicide." [9]From these above words we can find two important truths in Knechtges' research: the first is that his praise for the Faan-sau is not lack of knowledge about Chinese negative remarks on it; the next is his belief is that 
Yang's opposition to Chiu Yuan's suicide is "Confucian". For the first truth, it can be easily confirmed if one finished reading his marvelous works, but for the second truth, it presents some interestingly different understanding of Confucianism. As we have discussed, Chiu Yuan's suicide is a righteous deed encouraged by Confucius' "to do what is impossible against all odds if only he could be useful for the society." So Chiu Yuan's suicide is in compliance with Confucian doctrine. But in Knechtges' words, Yang Xiong's Faan-sau is a "Confucian' opposition to Chiu Yuan's suicide, in other words, Yang Xiong is Confucian, while Qu's suicide is non-Confucian. He explained in his dissertation that throughout the Han dynasty Chiu Yuan had been upheld as the paragon of Confucian virtue and his suicide was consider entirely justified. This was contrary to the traditional Confucian doctrine that declared when the time and conditions were not favorable to implementation of one's ideas or if the ruler was hostile and unsympathetic, it was best to withdraw from active participation in political life. Yang Shyong advocated this principle most of his life. Obviously, this appears to be a big divergence: The Faan-sau which is denounced as a rebellion against Confucianism is praised by Knechtges as a firm adherence to Confucianism. What is the root for these completely opposite ideas?

American traditional culture must play a vital role in Knechtges' understanding of Confucianism. Greatly influenced by the Western tradition of "consciousness of life", "humanistic thought" and "individualist spirit", when Knechtges interpreted Confucianism, he unconsciously filtered something incompatible with Western tradition. He abandoned Confucius' belief to do what one can do against all odds and to sacrifice one's individual interest for social benefits. What he absorbed from Confucianism is Mencius' (孟子) belief that "In obscurity, scholars would maintain their own integrity; in times of success, they would make perfect the whole empire.”（穷则独善其身；达则兼济天

下) From Knechtges' remarks on the Faan-sau, the filtration and variation of Eastern philosophy in the process of literature dissemination can be easily detected. Knechtges' interpretation of Confucianism is not the original and overall meaning of its Chinese one. His amicable attitude toward the Faan-sau is primarily because of the individualism and free will which can hardly be found in Chinese literature as early as in Han dynasty.

Michael Barnet praised the Faan-sau in a more direct way than Knechtges did. He said: "Yang Xiong was much concerned with defining the truths applicable to the organism, he cherished most the role of the social philosopher whose duty it was to explain to man how best to adapt to the organism. His concept of organism was not rigious to the degree that man, like an animal, was locked into a fixed mode of living or pattern of conduct. On the contrary, because man was rational, he could act upon concepts and principles that transcended the monotonous rigor of subhuman life; he could analyze and come to grips with the perplexities of the organism, and by means of his knowledge of the organism he could enhance his chances for survival and fulfillment."[10] Barnet advanced the argument of putting individualism and organism into opposite pillars which is the Western conventional thinking model of binary opposition, but he was aware of Yang's innovative way of combining the value of organism without denying the value of individual life, and shrewdly adjust man's sense to better protect his individual life and fulfill his ideals. In Barnet's view, Yang Xiong's thought is a great Eastern philosophy. However, Yang's attempt to keep a balance between individualism and organism was criticized as cowardice and non-action.

Chinese scholars denounce the Faan-sau, while American scholars praise it. Both sides do it under the influence of Confucianism. The Faan-sau's different encounters show us the variation of Chinese ancient literature in its oversea dissemination because it has been reshaped by Western assumptions and premises. Wai-lim Yip (叶维廉) once pointed out that cross-culture study must be carried out from both this and that sides, which means "we should not stick to only one side, we should not be locked to only one stand."[11] His insight of appreciating literature from both Eastern and Western perspectives provides a good way to better understand the value of the Faan-sau. Chinese scholars were once in a heated dispute about Yang's attitude to Confucianism. The voices of "pure Confucian" (醇儒), "variant Confucian" (变儒) and "non-Confucian" (非儒) led Yang Xiong study in a clamor. Maybe American scholars' voice can calm them down and provide a new perspective to illustrate Yang's thought in his motherland.

\section{Divergences on Yang Xiong's Imitation of his Predecessors}

It is widely acknowledged that Yang Xiong's "four great fu" have received influences from Sima Xiangru's "Zixu Fu" (《子虚赋》) and “Shanglin Fu" (《上林赋》). Besides, Liu Xie once pointed out that the characteristics of "tricky and disguised words" and "inclusion of God and demons" in Yang's “Ju Qin Mei Xin" (《剧秦美新》) was apparently an imitation of Sima's writing style. [12]Others also proved that "the Faan-sau" and "Tai Xuan" (《太玄赋》) are parodies of Chiu Yuan's Li Sao, and “Jie Chao" ( 《解嘲》) and “Jie Nan" ( 《解难》), though never entitled with "Fu”, were actually imitation of Dongfang Shuo's (东方朔) “ $\mathrm{DaKe}$ Nan” (《答客难》). Most Chinese scholars deny Yang's creativity in composing these writings. They held that imitation is a big drawback in Yang's writings.

While Nicholas Morrow Williams wrote in the abstract of his doctoral dissertation The Brocade of Words: Imitation Poetry and Poetics in the Six Dynasties: "Writing necessarily involves creative imitation of earlier models, even for the most accomplished writers from Virgil to Shakespeare and from Yang Xiong to Li Bai."[13] From these words, we can see Williams's high regard of Yang's 
writings, because he even equaled Yang to Virgil and Shakespeare in Western literature history and Li Bai (李白) in Chinese ancient literature. In the following argumentation he quoted some words in Ban Gu's "Han Shu" (班固《汉 书》): "He considered that there was no classic greater than the changes, so he composed the Great Mystery; no tradition greater than the Analects, so he composed the Model Saying; no primer for writing superior to the "Forester's Admonition", so he composed the "Regional Admonitions"; no Fu more profound than "Encountering Sorrow," so he "refuted" and "broadened" it; no rhapsody lovelier than those of Sima Xiangru, so he composed his four fu, in all of these he pondered the origin, relied on it as a model, and then cavorted way without restraint."'[14] Ban Gu's words were used as favorable remarks to prove that Yang was indeed a master of imitation by Williams in his dissertation, which is just opposite to Chinese scholars' purpose in quoting them, since these words are usually considered a criticism and they even reflect a disdain for Yang's writing technique by Chinese scholars. To support his idea that Yang's imitation and creation are actually two sides of the same coin and the tradition of dialectical assessment initiated by Ban $\mathrm{Gu}$ is influential in China, Williams then made use of Shen Dongqing's (沈冬青) “Yang Xiong: Cong moni dao chuangxin de dianfan" (《从模拟到创新的典范》), Chen Weien's (陈维恩) "Shi lun Yang Xiong fu de moni yu zhuanxing" (《试论扬雄赋的模拟与创新》) and Japanese scholar Taniguchi Hiroshi's "Yang Xiong 'kou ji' yu moni qianren_shi lun wenxue shumianhua yu qi yingxiang" (《扬 雄“口吃”与模拟前人一一试论文学书面化与其影响》) to support his conclusion that "Yang Xiong's imitation was only one stage in a process of composition whose results were entirely original."[15] But it seems that Williams has deliberately neglected a fact that the scholars' researches on Yang's imitation he mentioned above were all carried out at the end of last century or the beginning of the $21^{\text {st }}$ century: Shen's book was published in 1993, Chen's essay in 2003 and Taniguchi Hiroshi's essay collected in "New Views of Han, Wei and Six Dynasties Literature in the Twenty-first Century: A festschrift in Honor of Professor David R. Knechtges on His Sixtieth Birthday" in 2003. He filtered a truth that in most Chinese literary history, Yang's imitation has been regarded as a kind of retrogression. For example, Tang Yan (唐晏) in Qing dynasty once said: “Ziyun's (Yang xiong's style name) writing is best at imitation.......he had no other achievement except it. If asking about his own writing style that can make him prominent, the answer is nothing."[16] Therefore, Williams' conclusion only based on recent researches is obviously inadequate if he ignored so many negative remarks on Yang's imitation in Chinese history of literature criticism.

Williams defended Yang and said: "When Yang chose a work to imitate, he was not doing it merely as a literary exercise or to show off his ingenuity. Instead, he took some model from the past and transformed it according to his own needs." [17]And he then added that though all his works show stark differences from their models, perhaps the most striking example was "Refuting the Sao" (反骚). But in his opinion, although it is an imitation of the "Li Sao", it is also a kind of retraction, a formal rebuttal of the principal argument of the "Li Sao."

Although Williams' words about Yang's imitation are a little lavish in the eyes of his Chinese peers, one of his attempts should be duly appreciated. He tried to explore the root cause of Yang's imitation and found that Yang's "Refuting the Sao" was not unique, but part of a tradition of imitations and responses to Chiu Yuan that flourished throughout the Han. Actually, from Jia Yi's "Fu Mouring Chiu Yuan” (贾谊《吊屈原赋》) to Chuci compiler Wang Yi’s “Nine Longings” (《楚辞章句》编撰者王逸的《九思》), there were various literature works of this kind. It is reasonable for him to say that "This literary culture of imitation in the Han had roots in Chinese culture and thought, though, which are represented most vividly in Yang Xiong." [18] The Han dynasty is one of the acmes of Confucianism in China, Yang Xiong, influenced by Confucius' thoughts and wisdom, of course valued the maintenance and spread of Confucianism. The background of "proceeding with the argument in accordance with 'Jing'” (依经立义) encouraged literary imitation and it happened that Yang made use of imitation to its fullest. Williams' remarks inspire us to set Yang back into his own era and reassess his imitation objectively instead of kidnapping him to the present time and criticizing his lack of "originality."

When talking about literary imitation, Williams sternly opposes ancient Chinese metaphor of comparing "stacking up house upon house” (屋下架屋) to Yang Xiong's imitative literature. He appreciates the simile of comparing his literary composition to "construct a brocade" which derived from Liu Xi's (刘熙) famous definition of “wen” (文) in the Shi Ming (《释名》) in the Eastern Han: "Writing: just as one gathers the various colors to construct a brocade, so one gathers the various words to construct a phrase; writing is just like making a brocade.” (文者，汇集众彩以成锦绣; 汇集众字以成辞义, 如文绣然也。)[19] He commented that "brocade is a fitting metaphor because it is expansive: you take certain strands and motifs and keep on weaving them together, making a larger and larger fabric without any predetermined limit."[20] It is certain that in Williams' eyes, the $\mathrm{Fu}$ created by Yang Xiong is a piece of expansive brocade instead of a house stacked upon a house and imitation is a route one must take in the development of literature instead of a drawback to hamper literature creation.

In the beginning of his dissertation, Williams quoted a sonnet by Shakespeare: "So all my best is dressing old words new, Spending against what is already spent: For as the sun is daily new and old, So is my love still telling what is told." [21]To understand Williams' dialectical attitudes towards old and new as well as imitation and creation, it is necessary to recall Western tradition of "mimesis". Williams traces the tradition to Plato. Plato said in the final book of Republic that art is the mimesis of reality. But Socrates criticized the descriptive and misleading function of art by saying art is an 
imitation or mimesis of reality, hence inferior to, and distracting from, a proper understanding of reality. Aristotle famously followed Plato in characterizing mimesis as the essence of art, but he added mimesis didn't mean a naïve reproduction of reality, but instead involved the crafting of a plot, transforming and refining its materials. From these three great philosophers' argument on mimesis, it can be easily seen that in the Western poetic tradition, art is inherently relevant to imitation. No matter Williams considered Yang Xiong's imitation as an amazing literary gift instead of a weakness.

\section{Conclusions}

Comparative literature is a product of international literature exchanges and it grows along with the development of transport and communication across nations, languages, races, and civilizations. In the present era of "Globalization" which globalization and localization both pull literature into their own directions, a perspective of comparative literature becomes particularly crucial to keep better balance between these two opposite forces. In "The Variation Theory of Comparative Literature", Professor Cao Shunqing, president of Chinese Society for Comparative Literature, stressed the importance of study on "heterogeneity" and "variation" in international literature dissemination from the levels of cross-language, cross-culture and cross-civilization. He pointed out that previous comparative literature valued the comparability of homogeneity which was only feasible for comparative literature in the same civilization, but as the study object of this discipline has expanded to be of cross-civilization, the study of homogeneity is no longer evocative and inspiring as before. The study of heterogeneity is more meaningful than that of homogeneity since the communication and dialogues between different minds can bridge the gaps and clear up misunderstandings. Chinese and American scholars live in different civilizations and hence receive different influences from their cultural moulds and poetic traditions. It is natural that their researches on Yang Xiong's Fu display differences in background, paradigm, perspective and attitude. Through the comparative study of their divergences in researches on Yang Xiong's $\mathrm{Fu}$, a mutual interpretation, testimony, complementation and communication between Chinese and America can be gained. Besides, Zhang Longxi, chairman of International Comparative Literature Association, expressed gratitude to Western sinologists by saying "sinologists make contributions for their native people's understanding of foreign cultures......We respect these Western sinologists, because they introduce Chinese thought and culture to the West, enable Westerners to understand Chinese traditions, and promote the cultural communication between East and West."[22] Therefore, American scholars' research on Yang Xiong's Fu of course deserves the thoughtful considerations of Chinese scholars. Western research can not only enlighten Chinese scholars, it is also an integral part of international research on it which should be cherished by all comparatists.

\section{Acknowledgments}

This essay is an achievement of the project "Analysis of the Heterogeneities in Sino-US Yang Xiong Researches from Perspective of Comparative Literature" (SC16WY005) supported by Sichuan Federation of Social Sciences Circle. I am grateful to the fund to enable me to make research for this project.

\section{REFERENCES}

[1] Gong Kechang. "A Study on Chinese Fu". Shangdong: Shangdong University Press, 2010, P.36.

[2] Jiang Wenyan: "Introduction to 'The Han Rhapsody: A Study of the Fu of Yang Hsiung [52B.C-A.D.18]'”. International Sinology, 2015 (4), P.148.

[3] David R. Knechtges. "Studies of Han Dynasty Court Literature and Culture". Trans. Su Ruilong. Shanghai: Shanghai Translation Publishing House, 2013, P.80.

[4] Zhu Xi. "Chuci Jizhu". Shanghai: Shanghai Chinese Classics Publishing House, 1979, P.237.

[5] Liu XiZai. "Yi Ga". Shanghai: Shanghai Chinese Classics Publishing House, 1978, P.88.

[6] Gong Kechang. P.358.

[7] Knechtges, David Richard. "Yang Shyong, The Fhu, and Han Rhetoric". University of Washington,1968, preface.

[8] Ibid., P.306-307.

[9] Ibid., P.14.

[10] Michael Barnet. "Han Philosopher Yang Xiong: An Appeal for Unity in an Age of Discord". Georgetown University, 1983, P.174.

[11] Wai-lim Yip. "For the Lively Integral Life", Artistic View, 1994(4), P.10-15.

[12] Liu Xie. "Wenxin Diaolong”.Heilongjiang: Heilongjiang People Press, 2004, P.65.

[13] Nicholas Morrow Williams. "The Brocade of Words: Imitation Poetry and Poetics in the Six Dynasties". University of Washington, 2010, Abstract.

[14] The Han Shu Biography of Yang Xiong (53B.C.-A.D.18).Tempe, Arizona: Center for Asian Studies, 1982, P.59.

[15] Nicholas Morrow Williams. P.43.

[16] Tang Yan. "Lianghan Sanguo Xuean". Beijing: Zhonghua Book Company, 1986, P.553.

[17] Nicholas Morrow Williams.P.44.

[18] Ibid.

[19] James J. Y. Liu. "On wen and the 'aesthetic theory' of literature". Chinese Theories of Literature, Chicago: University of Chicago Press, 1975, P.100. 
[20] Nicholas Morrow Williams. P.48.

[21] Ibid, 1.
[22] Zhang Longxi. "Ten Essays on Chinese and Western Culture Researches”. Shanghai: Fudan University Press, 2005, P.114. 